\title{
Darwinism in a medical school
}

\author{
Sthapit $\mathbf{B}^{1}$, Dhungana $\mathbf{V}^{\mathbf{1}}$ \\ ${ }^{1}$ Intern, Kathmandu Medical College, Sinamangal
}

$\mathrm{C}^{\mathrm{e}}$ enturies ago, Charles Darwin postulated the theory of Natural Selection. In spite of many controversies, he suggested that life is a competitive struggle to survive, often in the face of limited resources. He offered that within a given population in a given environment, certain individuals possess characteristics that make them more likely to survive. The number of organisms with these traits increases as each generation passes on the advantageous combination of traits. Outmatched, individuals lacking the beneficial traits gradually decrease in number.

Today, this theory stands truer than at any time in the history. With increasing competition and advancement of the world, the fight for survival has become more intense, diffusing from nature to all human sectors and area. One of the eminent examples is 'a medical school'.

Few would disagree to the fact that a medical school is a ground for survival of the fittest. And those believed to be the fittest are the smart, intelligent people. The picture of a doctor to a layperson is that of a priest with a hotline to God, one who can cure any and all pains. Reflecting to this, the picture of a medical student is that of a serious, studious and intelligent person. Good schooling, good grades and a good brain are what determine the survival of a student in the medical school. This is the hearsay.

But the interesting twist is - the truth, to which all doctors and medical students would completely agree.

After 5 years in a medical school, as one looks back, it is more than apparent that the fight for survival here is not the game of smartness or brains only. It is not only academics. There is much more to it. There are moments and there are incidents with the experiences earned, the wounds endeavoured, the lessons learnt. It seems natural that those aspiring to face the agonies and sufferings of humans must first themselves become acquainted with it. So as the novice doctors tune their minds with thick books and endless knowledge, they simultaneously harden their hearts to stand the inhumane pressure that go side by side in medicine. Those who survive this endurance period survive the medical school. Then only do they earn the degree.

Knowledge, skill and character building is no doubt the very core of the education of medical school. But survival in the path to attain this education demands a wholesome fitness - intellectual along with physical, mental, psychological and often also financial. Studying here not only requires good memory and reasoning power but also continuous dedication, hard work, inquisitiveness and physical fitness. Overnight study sessions, hours of practical exams, long lectures and dissections - it almost makes the students ill. Confirm this from any intern.

"My first overnight study session - inflammation from Robin's Basis of Pathology landed up with a weeklong fever, teaching me to pace my sessions of studies for the rest of the years."

Moreover, one cannot realise how vast medicine is till $\mathrm{s} /$ he begins to study it. The introduction of human body - anatomical, biochemical and physiological - in the first couple of years make the novice apprehend how vast the problem is. The introduction to knowledge of diseases and power to combat them- in pathology and pharmacology respectively and all the other clinical subjects shows the medical student as to how insignificant $\mathrm{s} /$ he and their responsibility is.

There in the lecture halls and the book laden cubicles, we spend time studying and memorising - even a full night sleep and hearty meals are rare treats. It will not be an exaggeration to compare a medical student to a robot studying human body. The impact is so immense that it alters the whole biological rhythm and needs of the body.

Correspondence

Dr. Bonisha Sthapit

Kathmandu Medical College

Sinamangal, Kathmandu

E-mail: bonishaa@hotmail.com 
But still students keep going on. The driving force is the competition amongst fellow students, expectations of families and friends and above all, the gravity of the responsibility awaiting them. It is the matter of life and death and here, to err may be fatal.

The medical study not only builds on over our already existing foundation. It is so influential that it tends to change our inner self in numerous ways. It may be in terms of realisation of weak points, facing the dreaded fears, building courage and much more.

"I found myself facing my worst fear - the dead bodies. But as the years wore on, the bare handed dissections and post mortem examinations helped me to handle these fears and calm myself.",

Another change that many outsiders complain of is that a medical student unconsciously becomes reserved, proud and unsocial. In a way the claimed changes are just, bearing in mind the little time we spend with families and friends. After all, most of the time is spent with books and patients.

Remaining aloof from the joys and pains of near and dear ones is one of the biggest pressures on the psyche. It is difficult to sacrifice the prime of one's life - the twenties and thirties learning techniques to help fellow human. But as it is said, devotion to duty is not a sacrifice, it is a justification. This abstinence from worldly relations and materials is a very essential and crucial justification in the life of a medical student and so of a new, young doctor.

"My worst moment in MBBS was when I could not see my grandfather for the last time nor take part in his funeral rites - because I was taking my Ophthalmology final exams. This was when I felt I am leaving my family behind to do good for a bigger community and I actually understood the meaning of the justification to duty."

And when all these hardships are about to end, then comes the decisive hour - the examinations. Nothing exists but the books, the examiner and self. The lights of the dormitories never go off. Students live virtually on coffee and fast food (noodles). There is no difference of day and night. The pressure is so high that people even give up on the eleventh hour after countless days of studying. And surprisingly, even the smartest and the brightest are not immune to this exam-illness.

"We dreaded to enter the exam hall during our final $M B B S$ exams. The frightening results of the previous year, with almost 50\% failure, containing some of the top rankers developed all of us a kind of phobia."

Hence, in these ways, and many more, a medical student builds up his/her knowledge and skill with hours of study, dedication and efforts. S/he hardens his/ her conscience and character by coping with emotional, mental and psychological stressors. Fortunately, as in the temple of Aesculapius, deep wounds and scars miraculously heal and leave no disfigurement on face or psyche. Most of the medical students pass through all hurdles of medical school successfully. They grow with each hardship and prove themselves capable. These, who survive the selection, move on to live as the healers, the doctors. They move out into the world of pain and disease with rays of hope.

"Med school provides the best substantiation for Charles Darwin's theory of natural selection. For here we see in its cruellest form, survival of the fittest. Not the smartest as one should expect. But the fittest to cope with the inhumane pressures, the demands, made not only on the brain but on the psyche..."

These lines from Doctors by Erich Segal are for all those aspiring to enter a medical school. They must understand each word and prepare themselves for the Natural Selection of the medical school. Darwinism prevails, and prevails strongly with force in here.

\section{Reference}

1. Segal E. Doctors. UK: Bantam Dell. 1989. 